\title{
Life cycle assessment of advanced bioethanol production from pulp and paper sludge
}

\author{
Diogo Sebastião, Margarida S. Gonçalves, Susana Marques, César Fonseca ${ }^{1}$, Francisco Gírio, Ana C. Oliveira, \\ Cristina T. Matos*
}

Unidade de Bioenergia, Laboratório Nacional de Energia e Geologia, I.P., Estrada do Paço do Lumiar, 1649-038 Lisboa, Portugal

\section{H I G H L I G H T S}

- LCA was used to evaluate an ethanol plant converting pulp and paper sludge.

- Enzymatic hydrolysis and neutralisation of the $\mathrm{CaCO}_{3}$ are the environmental hotspots.

- Neutralisation and subsequent $\mathrm{CO}_{2}$ emissions is specific to this raw material.

- Two optimisation scenarios were developed (reduced $\mathrm{HCl}$ usage and co-fermentation).

\section{A R T I C L E I N F O}

\section{Article history:}

Received 21 December 2015

Received in revised form 10 February 2016

Accepted 11 February 2016

Available online 22 February 2016

\section{Keywords:}

Life cycle assessment

Bioethanol

Waste valorisation

Pulp and paper sludge

\begin{abstract}
A B S T R A C T
This work evaluates the environmental performance of using pulp and paper sludge as feedstock for the production of second generation ethanol. An ethanol plant for converting 5400 tons of dry sludge/year was modelled and evaluated using a cradle-to-gate life cycle assessment approach. The sludge is a burden for pulp and paper mills that is mainly disposed in landfilling. The studied system allows for the valorisation of the waste, which due to its high polysaccharide content is a valuable feedstock for bioethanol production. Eleven impact categories were analysed and the results showed that enzymatic hydrolysis and neutralisation of the $\mathrm{CaCO}_{3}$ are the environmental hotspots of the system contributing up to 85\% to the overall impacts. Two optimisation scenarios were evaluated: (1) using a reduced $\mathrm{HCl}$ amount in the neutralisation stage and (2) co-fermentation of xylose and glucose, for maximal ethanol yield. Both scenarios displayed significant environmental impact improvements.
\end{abstract}

(c) 2016 Elsevier Ltd. All rights reserved.

\section{Introduction}

Bioethanol is currently used in commercial gasoline blends, mainly produced through conventional first generation technology, which relies on dedicated energy crops competing with arable land for food and feed. The EU directive 2009/28/EC (European Commission, 2009) stipulates a mandatory target of $10 \%$ incorporation of renewable energy in the transport sector by 2020 and second-generation (advanced) biofuels produced from lignocellulosic wastes will count double towards this target. A revision of 2009/28/EC directive was recently approved by EU and shall soon enforce a cap of $7 \%$ on first generation biofuels as well as a non-binding reference

\footnotetext{
* Corresponding author. Current address: European Commission, Joint Research Centre (JRC), Institute for Environment and Sustainability (IES), Sustainability Assessment Unit, Via Fermi, 21021, Ispra, VA, Italy.

E-mail address: cst.matos@gmail.com (C.T. Matos).

1 Current address: Section for Sustainable Biotechnology, Aalborg University Copenhagen, A. C. Meyers Vænge 15, 2450 Copenhagen SV, Denmark
}

target of $0.5 \%$ for biofuels produced from lignocellulosic materials. In Europe, some demo and flagship plants are already deployed for advanced bioethanol production from lignocellulosic materials, namely Beta-Renewables' flagship plant in Crescentino (Italy), Inbicon's demo plant in Kalundborg (Denmark), Clariant's demo plant in Straubing-Munich (Germany), among others.

Pulp and paper sludge might also be an interesting feedstock for advanced bioethanol production due to its high polysaccharide content. Moreover, its usage for bioethanol production has the advantage of avoiding its disposal in landfill, thereby reducing the corresponding environmental and economic impact (Monte et al., 2009). Polysaccharides present in this sludge are highly accessible to enzymatic hydrolysis due to the physical and chemical processing undertook during pulp and paper manufacturing (Marques et al., 2008a). This characteristic avoids the costly pretreatment step usually required with unprocessed lignocellulosic feedstocks. In 2013, the Portuguese pulp and paper industry generated 350000 tons of dry sludge (2013 data from CELPA the Portuguese pulp and paper association). The feasibility of using 